\title{
Novel and characteristic CFTR mutations in Saudi Arab children with severe cystic fibrosis
}

E A El-Harith, T Dörk, M Stuhrmann, H Abu-Srair, A Al-Shahri, K-M Keller, M J Lentze, J Schmidtke

The molecular basis of CF in Arab populations still remains largely undocumented. Unravelling the common CFTR mutations in a specific population helps confirmation of the diagnosis of $\mathrm{CF}$, allows genetic counselling of CF families, and may yield information on how different mutations in the CFTR gene are related to the severity of the disease. These considerations prompted us to study the molecular aspects of the disease in CF children from the eastern region of Saudi Arabia.

\section{Patients and methods}

PATIENTS

Fourteen children with CF in this study, who belonged to 11 different families, came from cities in the eastern region of Saudi Arabia. The patients attended the clinics of Dammam Children's Hospital or Qatif Central Hospital during the past two years. One additional family with a single CF child originated from the United Arab Emirates and was treated at the University Hospital of Bonn in Germany. The clinical diagnosis, based on typical pulmonary/ gastrointestinal findings, was confirmed by an abnormal sweat chloride result $(\geqslant 60 \mathrm{mmol} / \mathrm{l})$ in each case. Sweat chloride was measured by pilocarpine iontophoresis using an Orion sweat chloride analyser (Orion Research Incorporated, USA).

The age of the patients at diagnosis, their clinical history, and the familial relationship between their parents were recorded. In 10 out of 12 families the parents were first degree cousins, that is, a consanguinity rate of $83 \%$. Severity of the disease was judged by incidence of recurrent chest infections, in particular with Pseudomonas aeruginosa, failure to thrive, and repeated hospital admissions. The chest presentation was assessed by the four chest sounds: pneumonia, crepitations, rhonchi, and tachypnoea.

Table 1 CFTR mutations in 12 Arab CF families

\begin{tabular}{lllll}
\hline Mutation & $\begin{array}{l}\text { Nucleotide } \\
\text { change }\end{array}$ & Location & $\begin{array}{l}\text { Allele } \\
\text { frequency }\end{array}$ & Reference \\
\hline $3120+1 \mathrm{G} \rightarrow \mathrm{A}$ & $3120+1 \mathrm{G} \rightarrow$ A Intron 16 & $3(21 \%)$ & 14 \\
$\mathrm{~N} 1303 \mathrm{~K}$ & $4041 \mathrm{C} \rightarrow \mathrm{G}$ & Exon 21 & $2(14 \%)$ & 12 \\
$1548 \mathrm{delG}$ & $1548 \mathrm{delG}$ & Exon 10 & $2(14 \%)$ & This study \\
$406-2 \mathrm{~A} \rightarrow \mathrm{G}$ & $406-2 \mathrm{~A} \rightarrow \mathrm{G}$ & Intron 3 & $1(7 \%)$ & This study \\
$2043 \mathrm{delG}$ & $2043 \mathrm{delG}$ & Exon 13 & $1(7 \%)$ & 13 \\
I1234V & $3832 \mathrm{~A} \rightarrow \mathrm{G}$ & Exon 19 & $1(7 \%)$ & 15 \\
Unknown & & & $4(29 \%)$ &
\end{tabular}

Mutations identified in 12 Arab CF families are listed by decreasing frequency. Only one sib of a family was counted, and only one occurrence of the mutation in consanguineous unions was considered to achieve more accurate estimates of the allele frequencies. \begin{abstract}
and were observed to present with hypoelectrolytaemia and metabolic alkalosis ${ }^{6}$ and in some cases with hepatobiliary disease. ${ }^{7}$ populations and has helped the elucidation of forms of the disease. ${ }^{1}$

The incidence of $\mathrm{CF}$ varies in different nations with the highest incidence of about 1:2000 in white populations. Although CF is generally considered to be rare in Arabic and African children, it is likely that many of these children remain undiagnosed owing to the lack of proper diagnostic facilities and public awareness of the disease. In Saudi Arabia, 1 in
\end{abstract}




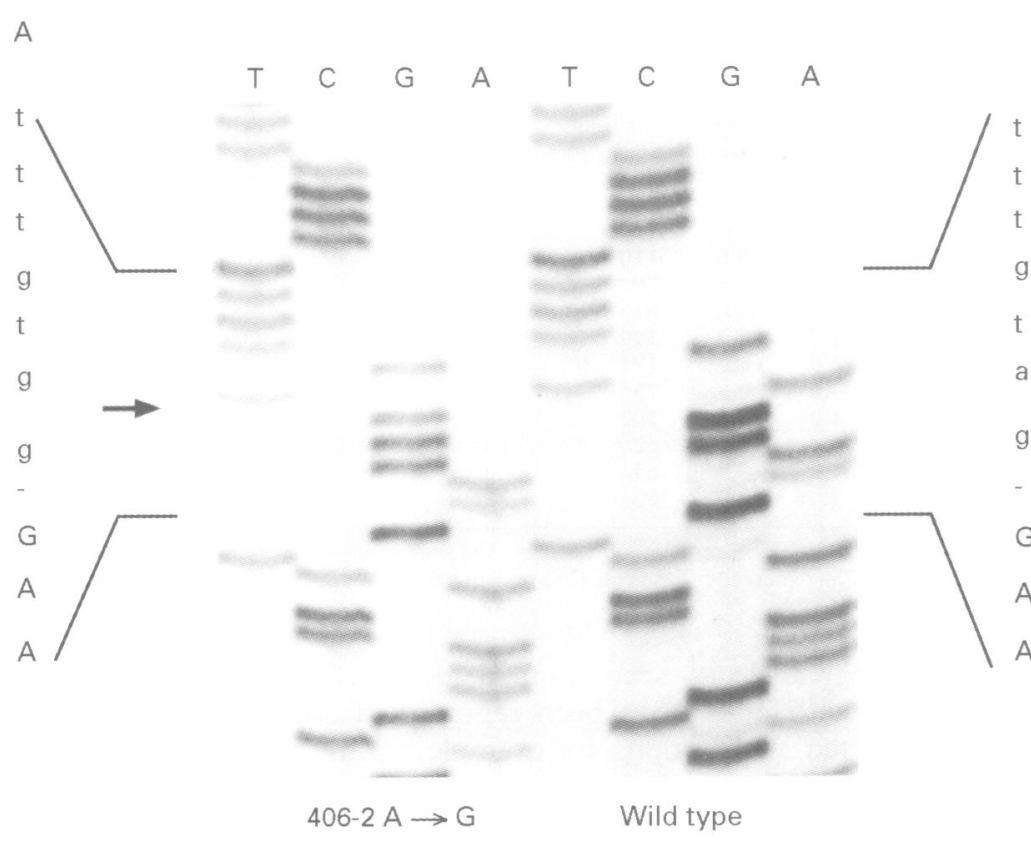

B

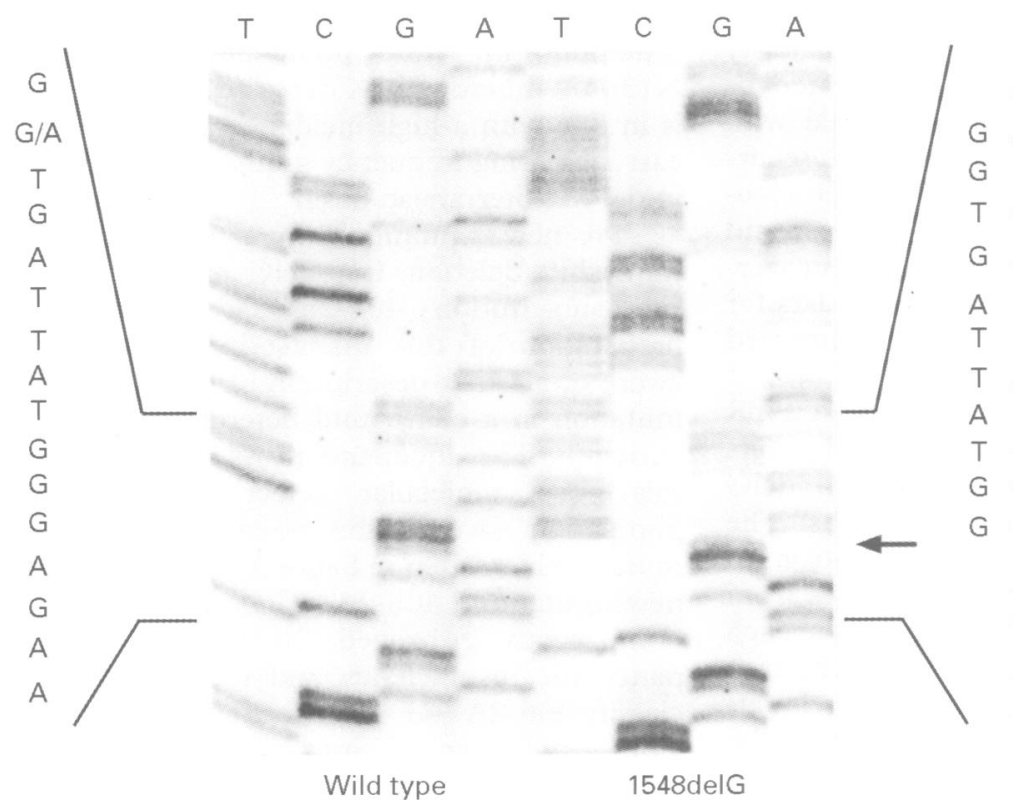

Figure 1 (A) Left: autoradiograph showing the 406-2A $\rightarrow G$ mutation in intron 3 of the CFTR gene (homozygous) by direct sequencing of the PCR product. (B) Right: autoradiograph showing the 1548 del $G$ mutation in exon 10 of the CFTR gene (heterozygous) by direct sequencing of the PCR product.

Following informed consent of the parents, blood samples were collected from the patients, their parents, and affected sibs. Isolation of high molecular weight DNA from leucocytes was performed according to standard procedures.

\section{MUTATION ANALYSIS}

DNA sequences spanning individual exons and flanking intron sequences of the CFTR gene were amplified by the polymerase chain reaction (PCR). For direct mutation analyses, PCR products were digested with the respective restriction enzyme and the fragments were separated by electrophoresis using a 3\% NuSieve/1\% SeaKem agarose gel. Mutagenesis primers were designed for some mutations (R117H， 1717-1G $\rightarrow$ A， G542X, 2143delT, $3272-26 \mathrm{~A} \rightarrow \mathrm{G}$, and $\mathrm{N} 1303 \mathrm{~K}$ ) to create artifi- cial restriction enzyme sites. Deletions of two or more base pairs were screened for by electrophoresis using a native $12 \%$ polyacrylamide gel. The 20 common CFTR mutations that were screened for were $\Delta \mathrm{F} 508, \Delta \mathrm{I} 507$, 1677delTA, R347P, R347H, R553X, G551D, G542X, N1303K, 3849+10KbC $\rightarrow$ T, R334W, $\mathrm{I} 336 \mathrm{~K}, 2789+5 \mathrm{G} \rightarrow \mathrm{A}, \quad 1717-1 \mathrm{G} \rightarrow \mathrm{A}, \quad 3272-$ $26 \mathrm{~A} \rightarrow \mathrm{G}, \quad \mathrm{Y1092X}, 2143 \mathrm{delT}, \mathrm{W} 1282 \mathrm{X}$, $\mathrm{R} 117 \mathrm{H}$, and the $5 \mathrm{~T}$ allele. PCR products from unidentified alleles were subsequently analysed for unknown mutations and DNA polymorphisms using single strand conformation polymorphism (SSCP) analysis as described by Orita et al. ${ }^{9}$ PCR primers and SSCP conditions have been described elsewhere. ${ }^{10}$ Samples showing aberrant migration were directly evaluated by DNA sequencing according to the method of Sanger $e t$ al ${ }^{11}$ using a Sequenase 2.0 PCR product sequencing kit (Amersham/ USA). Confirmation of the detected mutations in the PCR products of the patients' parents was performed by digestion using the appropriate restriction enzymes and electrophoresis.

\section{Results}

Screening of the CF chromosomes for 20 common CFTR mutations (first step screening) showed only one mutation, N1303K in exon 21. All other mutations reported here were detected in the second step of screening. These mutations were 2043delG, $3120+1 \mathrm{G} \rightarrow \mathrm{A}$, $1548 \mathrm{delG}, \mathrm{I} 1234 \mathrm{~V}$, and $406-2 \mathrm{~A} \rightarrow \mathrm{G}$. The three prominent mutations in our sample of $12 \mathrm{Arab}$ CF families were $3120+1 \mathrm{G} \rightarrow \mathrm{A}, \mathrm{N} 1303 \mathrm{~K}$, and 1548delG (table 1).

Two novel mutations were detected in this study and were reported to the Cystic Fibrosis Genetic Analysis Consortium in 1996. The first new CF allele was a splice mutation which changes an $A$ to a $G$ at nucleotide $406-2 A \rightarrow G$ affecting the conserved AG dinucleotide of the acceptor splice site of intron 3 (fig 1A). This mutation was detected in the homozygous state in a 20 month old CF child. The girl had been diagnosed at birth because of meconium ileus and since then had suffered from pancreatic insufficiency and failure to thrive. Her parents are first cousins and originate from the United Arab Emirates. The mutation 406-2A $\rightarrow$ G could be confirmed and screened for by restriction analysis as it abolishes a recognition site for the restriction enzyme EcoNI (not shown).

The second new CFTR allele was the frameshift mutation $1548 \mathrm{del}$ in exon 10 involving deletion of one of three guanine nucleotides at positions 1548-1550. This mutation results in a premature stop signal 54 codons downstream and was seen in two apparently unrelated Saudi Arab families. In the first family, two compound heterozygous sibs, a girl and a boy aged 4 months and 7 years, respectively, both carried the N1303K mutation $^{12}$ on the other allele. Although pancreatin had to be administered to both sibs, their height and weight development was near normal and there has been no need for hospital admissions so far. In the second family, a single CF child carried 1548delG with 
Table 2 CFTR mutation genotypes and clinical phenotypes of 12 Arab children with cystic fibrosis

\begin{tabular}{|c|c|c|c|c|c|c|c|c|}
\hline \multirow{2}{*}{$\begin{array}{l}\text { Patient } \\
\text { No }\end{array}$} & \multirow[b]{2}{*}{ Genotype } & \multirow[b]{2}{*}{ Sex } & \multicolumn{2}{|l|}{ Age } & \multirow{2}{*}{$\begin{array}{l}\text { Sweat } \\
\text { chloride } \\
\text { (mmolll) }\end{array}$} & \multirow{2}{*}{$\begin{array}{l}\text { Meconium } \\
\text { ileus }\end{array}$} & \multirow{2}{*}{$\begin{array}{l}\text { Pancreatic } \\
\text { status }\end{array}$} & \multirow{2}{*}{$\begin{array}{l}\text { Pseudomonas } \\
\text { aeruginosa } \\
\text { colonisation }\end{array}$} \\
\hline & & & $c$ & ad & & & & \\
\hline 4075 & $406-2 A \rightarrow G / 406-2 A \rightarrow G$ & $\mathrm{~F}$ & 1.5 & $a b$ & 90 & Yes & PI & No \\
\hline CF30 & $1548 \mathrm{delG} / \mathrm{N} 1303 \mathrm{~K}$ & $\mathrm{~F}$ & 0.3 & $a b$ & 180 & No & PI & No \\
\hline CF32 & 1548delG/N1303K & $\mathbf{M}$ & 7.0 & 0.8 & 110 & No & PI & No \\
\hline CF40 & 1548delG/unknown & $\mathbf{M}$ & 1.0 & 0.5 & 70 & No & PI & Yes \\
\hline CF01 & $2043 \mathrm{delG} / 2043 \mathrm{delG}$ & $\mathbf{F}$ & $0.3^{*}$ & $a b$ & 65 & Yes & PI & Yes \\
\hline CF10 & $3120+1 \mathrm{G} \rightarrow \mathrm{A} / 3120+1 \mathrm{G} \rightarrow \mathrm{A}$ & $\mathbf{M}$ & 2.7 & 0.7 & 129 & No & PI & Yes \\
\hline CF16 & $3120+1 \mathrm{G} \rightarrow \mathrm{A} / 3120+1 \mathrm{G} \rightarrow \mathrm{A}$ & $\mathrm{F}$ & 3.0 & $a b$ & 121 & Yes & PI & Yes \\
\hline CF46 & $3120+1 \mathrm{G} \rightarrow \mathrm{A} / 3120+1 \mathrm{G} \rightarrow \mathrm{A}$ & M & 4.6 & 0.3 & 75 & No & PI & Yes \\
\hline CF49 & $3120+1 \mathrm{G} \rightarrow \mathrm{A} / 3120+1 \mathrm{G} \rightarrow \mathrm{A}$ & M & 1.0 & 0.1 & 100 & No & PI & Yes \\
\hline CF25 & $\mathrm{I} 1234 \mathrm{~V} / \mathrm{I} 1234 \mathrm{~V}$ & $\mathbf{F}$ & 5.5 & 0.5 & 62 & No & PI & Yes \\
\hline CF28 & I1234V/I1234V & F & 1.0 & 0.5 & 65 & No & PS & No \\
\hline CF19 & N1303KN1303K & F & 2.6 & 2.0 & 60 & No & PI & Yes \\
\hline
\end{tabular}

Clinical features of 12 Arab CF children with identified CFTR mutation genotypes. Age is given in years; $c=$ current age; ad=age at diagnosis; $a b=a$ birth; $P I=$ pancreatic insufficient; $P S=$ pancreatic sufficient. One patient $\left({ }^{\star}\right)$ died at 0.3 years of age. Patients $30 \&$ $32,46 \& 49$, and $25 \& 28$ are sibs.

an unidentified mutation on the other allele. This 1 year old girl had severe disease with failure to thrive and was already infected with Pseudomonas aeruginosa. The nucleotide sequence of exon 10 showing the heterozygous frameshift mutation 1548 delG is shown in fig $1 B$.

Presentation of cystic fibrosis in the majority of children in this study could be rated as severe. Many of the children presented with pancreatic insufficiency, failure to thrive, recurrent chest infections, particularly with Pseudomonas aeruginosa, recurrent diarrhoea, and required frequent hospital admissions, on average four to six times annually. Clinical data for all 12 children with genetically confirmed cystic fibrosis are shown in table 2 .

Most children with homozygous CFTR mutations presented with a severe form of CF. One child homozygous for the 2043delG deletion $^{13}$ died at the age of 4 months. The splicing mutation $3120+1 \mathrm{G} \rightarrow \mathrm{A}^{14}$ in intron 16 was detected in three unrelated families from Saudi Arabia with homozygous patients in each family. Each of the four homozygous children was pancreatic insufficient and severely affected in early childhood confirming that the $3120+1 \mathrm{G} \rightarrow \mathrm{A}$ mutation represents a severe $\mathrm{CF}$ allele. The I1234V mutation ${ }^{15}$ was seen in the homozygous state in two sisters (aged 5 months and 5 years) who presented with failure to thrive and recurrent diarrhoea. However, the symptoms may not be solely related to $\mathrm{CF}$ since both girls had relatively low sweat chloride values (65 and $62 \mathrm{mmol} / \mathrm{l}$, respectively) and the younger sister was pancreatic sufficient and free from chest infections. These two girls originated from a real Arab Bedouin tribe, whose ancestral generations have been confined to living in this region.

\section{Discussion}

Molecular studies on CFTR gene mutations in Arab populations up to the present time are scarce or undocumented. Here, we have analysed the entire coding region and flanking intron sequences of the CFTR gene in a sample of 15 Arab children with CF. Despite this extensive screening, some $30 \%$ of alleles remain unidentified. Mutations in the unscreened non-coding regions or gross deletions may account for the remaining alleles that have escaped our detection. Similar detection rates have been reported in other oriental populations, for example, from Tunisia, ${ }^{16}$ Israel, ${ }^{17}$ and Turkey (Onay et al, submitted). The major CF mutation in white populations, $\Delta \mathrm{F} 508,{ }^{2}$ was not found in any of the Saudi families investigated. Out of 20 of the most common mutations in white populations, only the N1303K mutation was detected. This finding is in line with a high incidence and a west to east increasing frequency gradient of N1303K in the Mediterranean basin. ${ }^{16-18}$

Two new mutations were detected, the frameshift deletion 1548delG and the splice site substitution $406-2 A \rightarrow G$. During the preparation of this manuscript we became aware of another description of the 1548delG mutation in a compound heterozygous Saudi patient. ${ }^{19}$ The independent identification of this novel molecular defect in the same population favours the possibility that the mutation has arisen in Saudi Arabia. The other new mutation, 406-2A $\rightarrow G$, was seen in a homozygous girl aged 20 months, whose pancreatic insufficiency and meconium ileus classify $406-2 A \rightarrow G$ as a severe allele. This previously unknown CF mutation might also be population specific.

Many other mutations detected in this study were homozygous in the affected patient. This may be explained by the relatively high rate of consanguinity found among parents in this study $(83 \%)$. In published reports, an even higher rate of consanguinity $(88 \%)$ was found in Saudi families with CF children. ${ }^{7}$ Most children with homozygous CFTR mutations in our study presented with severe CF. The splicing mutation $3120+1 \mathrm{G} \rightarrow \mathrm{A}$ in intron 16 , which was first reported by Macek et $a l^{14}$ in AfricanAmerican patients, is of particular interest as it was identified here in three unrelated families from Saudi Arabia with homozygous patients in each family. This mutation has recently also been detected in native African patients and it was considered to be a frequent CFTR mutation in African populations. ${ }^{20}$

Our study sheds light on the spectrum of hitherto unknown CFTR gene mutations in Saudi Arab patients and the associated presentation of cystic fibrosis in this population. The information depicted here may facilitate the design of appropriate strategies for genetic 
testing of patients and carriers in this region of the world, where $\mathrm{CF}$ is probably an underdiagnosed disease.

We are grateful to Miss Michaela Finsel for her skilful help in the preparation of the manuscript. With appreciation we acknowledge the generous grant from the Alexander von Humbold Foundation, Bonn (Bad Godesberg), Germany, which made Foundation, Bonn
this work possible.

1 Welsh, MJ, Tsui LC, Boat TF, Beaudet AL. Cystic fibrosis. In: Scriver CR, Beaudet AL, Sly WS, Valle D, eds. The metabolic and molecular bases of inherited disease. 7 th ed. New York: McGraw-Hill,1995:3799-876.

2 Kerem BS, Rommens JM, Buchanan JA, et al. Identification of the cystic fibrosis gene: genetic analysis. Science of the cystic fib

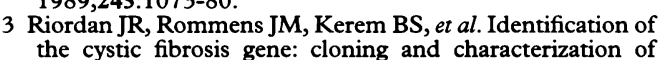
the cystic fibrosis gene: cloning and characterizat

4 Rommens JM, Iannuzi MC, Kerem B, et al. Identification of the cystic fibrosis gene: chromosome walking and jumping. Science 1989;245:1059-65.

5 Mathew PM, Hamdan JA, Nazer H. Cystic fibrosis presenting with recurrent vomiting and metabolic alkalosis. Eur $\mathcal{F}$ Pediatr 1991;150:264-6.

6 Nazer H, Riff E, Sakati N, et al. Cystic fibrosis in Saudi Arabia. Eur F Pediatr 1989;148:330-2.

7 Nazer H, Rahbeeni Z. Cystic fibrosis and the liver - a Saudi experience. Ann Trop Paediatr 1994;14:189-94.

8 Zielenski J, Rozmahel R, Bozon D, et al. Genomic DNA sequence of the cystic fibrosis transmembrane conductance regulator (CFTR) gene. Genomics 1991;10:214-28.

9 Orita $M$, Suzuki Y, Sekiya T, Hayashi K. Rapid and sensitive detection of point mutations and DNA polymorphism using polymerase chain reaction. Genomics $1989 ; 5: 874-9$.

10 Dörk T, Mekus F, Schmidt K, et al. Detection of more than 50 different CFTR mutations in large group of German cystic fibrosis patients. Hum Genet 1994;94:533-42.
11 Sanger F, Nickler S, Coulson AR. DNA sequencing with chain-terminating inhibitors. Proc Natl Acad Sci USA 1977;74:5463-7.

12 Osborne L, Knight R, Santis G, Hodson M. A mutation in the second nucleotide binding fold of the cystic fibrosis gene. Am f Hum Genet 1991;48:608-12.

13 Fanen $\mathrm{P}$, Ghanem $\mathrm{N}$, Vidaud $\mathrm{M}$, et al. Molecular characterization of cystic fibrosis: 16 novel mutations identified by analysis of the whole cystic fibrosis conductance transmembrane regulator (CFTR) coding regions and splice site junctions. Genomics 1992;13:770-6.

14 Macek M Jr, Mackova A, Hamosh A, et al. Identification of common CF mutations in African-Americans with cystic common CF mutations in African-Americans with cystic Genet 1997;60:1122-7.

15 Claustres M, Laussel M, Desgeorges M, et al. Analysis of the 27 exons and flanking regions of the cystic fibrosis gene: 40 different mutations account for the $91.2 \%$ of the mutan alleles in southern France. Hum Mol Genet 1993;2:120913.

16 Messaoud T, Verlingue C, Denamur E, et al. Distribution of CFTR mutations in cystic fibrosis patients of Tunisian origin: identification of two novel mutations. Eur $\mathbf{f} \mathrm{Hum}$ Genet 1996;4:20-4.

17 Kerem E, Kalman YM, Yahav Y, et al. Highly variable incidence of cystic fibrosis and different mutation distribution among different Jewish ethnic groups in Israel. Hum Genet among different

18 Osborne L, Santis G, Schwarz M, et al. Incidence and expression of the N1303K mutation of the cystic fibrosis (CFTR) gene. Hum Genet 1992;89:653-8.

19 Kambouris M, Meyer BF, Banjar H, et al. Identification of two novel CFTR exonic deletions (425del42 and $1549 \mathrm{delG}$ ) in cystic fibrosis (CF) patients by mutation detection enhancement (MDE) heteroduplex analyses. Possible founder effect associated with the 1540AG polymorphism. Am 7 Hum Genet Suppl 1996;59:A397, 2319.

20 Carles S, Desgeorges M, Goldman A, et al. First report of CFTR mutations in black cystic fibrosis patients of southern African origin. $\mathcal{F}$ Med Genet 1996,33:802-4. 